\title{
CLASSIFICACÃO DOS INGRESSOS NA GRADUAÇ̃̃O EM EDUCAÇÃO FÍSICA REFERENTE AOS CONTEÚDOS DA CULTURA CORPORAL
}

\author{
Fabiano José Teixeira Silveira \\ Bruna Muller Cardoso**
}

RESUMO: A educação escolar é o meio pelo qual os conhecimentos e as experiências acumuladas pelas gerações anteriores são transmitidos de maneira sistematizada. A educação física como disciplina escolar busca a compreensão e a utilização da linguagem corporal, reconhecendo manifestações corporais. Para os ingressos na graduação em educação física, que já concluíram o ensino médio, essa reflexão objetivada pelas diretrizes da educação em nosso Estado ficou bem definida ou eles entenderam apenas a "parte prática"? Assim, este estudo visa classificar o conhecimento sobre a cultura corporal dos acadêmicos ingressantes no curso de educação física da UniCesumar, de acordo com as diretrizes da educação para o Estado do Paraná. Trata-se de uma pesquisa descritiva, com amostra de 57 acadêmicos matriculados no primeiro ano da graduação em educação física da UniCesumar - unidade de Maringá - PR. O instrumento para coleta de dados foi um questionário validado, aplicado pelo autor, após a assinatura do TCLE, depois da aprovação pelo CEP. Os dados foram tabulados por meio da estatística descritiva e discutidos na tentativa de responder as questões iniciais. Por fim, podemos classificar o conhecimento da amostra pelos itens que demonstram mais conhecimentos na seguinte ordem: jogos e brincadeiras, dança, esportes, lutas e ginástica.

PALAVRAS-CHAVE: Cultura corporal; Educação; Educação física escolar.

\section{CLASSIFICATION OF UNDERGRADUATES IN PHYSICAL EDUCATION ACCORDING TO BODY CULTURE}

ABSTRACT: Schooling is the means by which knowledge and experience accumulated during generations are systematically transmitted. The discipline Physical Education requires comprehension and use of body language and acknowledges body manifestations. Has the above statement, based on the education guidelines of the state of Paraná, been well-defined or did first year undergraduates

Graduado em Educação Física pelo Centro Universitário de Maringá (UNICESUMAR), Brasil.

E-mail: fabianojts@hotmail.com

* Doutora em Biociências e Fisiopatologia Aplicadas à Farmácia (UEM); Docente no curso de Educação Física do Centro Universitário de Maringá (UNICESUMAR), Brasil. 
merely understand the 'practical section'? Current descriptive analysis classifies knowledge on body culture of first year students in the Physical Education Course at UniCesumar according to the educational guidelines of the state of Paraná, Brazil. Sample comprised 57 first year undergraduates of the Physical Education Course of the UniCesumar in Maringá, Brazil. A validated questionnaire was applied by the author for the collection of data after free consent was given and approval by CEP. Data were tabulated by descriptive statistics and the first issues were discussed. Knowledge may be classified by the items with the highest rate of knowledge: games, dance, sports, contests and gymnastics.

KEY WORDS: Body culture; Education; School Physical Education.

\section{INTRODUÇÃO}

A educação é uma prática social que acontece em várias instituições, ou seja, a prática educativa é uma atividade humana necessária à existência e ao funcionamento das sociedades. Toda a sociedade transmite seus conhecimentos por meio da educação, seja no modelo "conhecido" de escola ou não. A prática educativa é o processo de prover aos indivíduos os conhecimentos e experiências culturais necessárias à transformação do meio social pelas necessidades econômicas, sociais e políticas. Por exemplo, para pescadores, os mais jovens devem aprender as técnicas, períodos, iscas e o navegar. É necessário saber o que fazer em alto mar para sua sobrevivência. A educação escolar é um sistema de instrução e ensino com propósitos intencionais. Por meio da educação escolar é que se democratizam os conhecimentos e as experiências acumuladas pelas gerações anteriores (LIBANEO, 1994).

Para Rodrigues (2012) e Saviani (2008), no Brasil colonial, a primeira organização educacional conhecida foi trazida pelos Jesuítas em meados do século 16, logo após o seu descobrimento, quando o país respondia a Portugal. Com a expulsão dos jesuítas pelo marquês de Pombal, nasce uma tentativa de estabelecer uma escola pública de responsabilidade do Estado. Após o período pombalino ocorre a chegada da família real ao Brasil, fase conhecida como o período Imperial, quando novamente ocorreram mudanças na educação em favorecimento à elite 
que veio residir na colônia. Em paralelo, houve a tentativa de criar uma educação pelo poder público. Somente na primeira república entre os séculos XVIII e XIX que ocorre a descentralização do ensino dando liberdade aos Estados de criar suas instituições de ensino.

Durante a Segunda República, já no século 20, ocorrem os movimentos renovadores da educação. A educação era considerada a resposta para a modernização do país, sendo criado o Ministério da Educação e da Saúde e a Constituição de 1934, que já proporcionava o direito à educação. Durante o Estado Novo é proclamada a Constituição de 1937 e são criadas as instituições que mais tarde se transformariam no INEP - Instituto Nacional de Estudos Pedagógicos e a UNE - União Nacional dos Estudantes. O ensino "colegial" passa a ser dividido em "clássico" e "científico", perdendo em parte sua característica de preparação para o ensino superior. Porém, ainda existia a obrigação de o governo manter o ensino como direito de todos (RODRIGUES, 2012).

Na Quarta República ou República Populista (1946 - 1964) surge uma nova Constituição com a obrigação do ensino primário e dá poder à União de legislar sobre as diretrizes e bases da educação nacional. Em 1961 é promulgada a lei n ${ }^{\circ}$. 4.024 que fixa as Diretrizes e Bases da Educação Nacional, alterando a estrutura da educação e entre outros, reconhece os estabelecimentos de ensino oficiais e particulares. Neste período é lançado o Plano Nacional de Educação (PNE). No decorrer do período militar (1964-1985), houve a modernização do país baseado no modelo norte-americano (RODRIGUES, 2012).

Em 1985, com o fim da ditadura militar se inicia a Nova República, quando é promulgada a Constituição de 1988, que entre outros, institui um Estado Democrático, modelo este que conhecemos atualmente. A educação física escolar, de acordo com o Coletivo de Autores (2012), é a disciplina que trata da cultura corporal, que será configurada de maneira que seu estudo permita a expressão corporal como linguagem. A linguagem é a capacidade do homem de dar sentido às coisas e as compartilhar. Conforme o previsto em lei, cabe à União avaliar a educação em todo território brasileiro. Por exemplo, para avaliar o ensino médio é realizado o ENEM (Exame Nacional do Ensino Médio). O ENEM é um instrumento de avaliação dos conhecimentos e habilidades adquiridas pelos alunos. O resultado do ENEM 
também é utilizado pelo governo e instituições de ensino como critério para acesso à educação superior, concessão de bolsas de estudo e subsídio para políticas públicas em educação (BRASIL, 2014).

A educação física dentro do grupo das linguagens, busca a compreensão e a utilização da linguagem corporal, reconhecendo manifestações corporais, hábitos corporais em relação às necessidades de movimento e como meio de interação social. Apesar de todo o amparo legal, os direcionamentos e metodologias propostas, será que os alunos concluintes do ensino médio possuem tais conhecimentos previstos nas DCE? Quais habilidades motoras estes ex-alunos adquiriram referente aos elementos da cultura corporal? Assim, este estudo objetiva classificar o conhecimento sobre a cultura corporal dos acadêmicos ingressantes no curso de educação física da UniCesumar, de acordo com o proposto pelas diretrizes curriculares da educação para o ensino médio no Estado do Paraná. Ainda, como objetivo específico, verificar a razão pela qual a amostra decidiu cursar educação física.

A Constituição de 1988, entre vários itens, assume que a educação é um direito social. Promove o ensino público gratuito, educação básica gratuita sendo obrigatória dos quatro aos 17 anos e a oferta de ensino noturno regular adequado às condições do educando. Entre outras atribuições, a União assume a organização do sistema federal de ensino e seus territórios, objetivando um padrão mínimo de qualidade. A hierarquia da educação passa a ser União, Estados e municípios. Por fim, a lei criou o Plano Nacional de Educação (PNE), com o objetivo de articular o sistema nacional de educação com duração decenal (BRASIL, 2015).

Após sua publicação, a Lei de Diretrizes e Bases da Educação Nacional (LDB) sofreu alterações, sendo sua mais recente versão a lei no 9.394 de 20/12/1996. Nela a educação é definida como "todos os processos formativos que se desenvolvem na vida" em diversas esferas e regulamenta a educação escolar, que se desenvolve por meio do ensino. Adiante, o documento orienta sobre a educação básica, obrigatória e gratuita na faixa etária citada anteriormente. Organiza a educação em pré-escola, ensino fundamental e ensino médio e dispõe sobre ensino público especializado gratuito. Para aqueles que não puderam concluí-lo em idade própria, há oferta de ensino em horário noturno e educação para jovens e adultos. Mantém livre o ensino à iniciativa privada, cumprindo as normas vigentes da educação brasileira (BRASIL, 2015). 
De acordo com o PNE, a União em conjunto com os Estados e municípios direciona a educação infantil, o ensino fundamental e o ensino médio, graduação e pós-graduação. Cabe à União a coordenação da política nacional de educação, aos Estados e municípios em executar o disposto pela União e gerir seu patrimônio. Ainda esclarece sobre as categorias das instituições de ensino como públicas (as que são mantidas pelo Poder Público) e privadas (as que sejam administradas por pessoa física ou jurídicas de direito privado), estendendo-se em outros tipos de instituições, como, comunitárias, confessionais e filantrópicas (BRASIL, 2015).

Os currículos da educação básica devem por força da lei ser de base nacional comum, permitindo características regionais. A educação física, integrada à proposta pedagógica da escola, é componente curricular obrigatório, porém, sendo facultativa a alunos com jornada de trabalho igual ou superior a 06 horas diárias; maiores de 30 anos de idade, prestadores de serviço militar inicial ou similar, os amparados pelo decreto-lei $\mathrm{n}^{\mathrm{o}}$. 1.044 de 21/10/69 (portadores de algumas doenças, distúrbios ou amparados por laudo médico) e aos que tenham prole (BRASIL, 2015).

Para os níveis de ensino, a lei estabelece que no ensino infantil seja trabalhado o desenvolvimento integral da criança até os cinco anos, em seus aspectos físico, psicológico, intelectual e social. Já o ensino fundamental, que se inicia aos seis anos de idade, tem por objetivo a formação básica do cidadão, desenvolvendo a capacidade de aprender (leitura, escrita e cálculo), a compreensão do ambiente natural, social, sistema político, tecnológico, artístico e outros valores que fundamentem a sociedade. Ainda objetiva a capacidade de aprendizagem (formação de atitudes e valores), o fortalecimento dos vínculos familiares, a solidariedade humana e tolerância recíproca. O ensino médio é a etapa final da educação básica, que objetiva consolidar e aprofundar os conhecimentos adquiridos no ensino fundamental, permitindo o prosseguimento de estudos, preparação básica para o trabalho, cidadania, aprimoramento como pessoa humana, ética e autônoma intelectualmente portadora de pensamento crítico. Também almeja a compreensão dos fundamentos científico-tecnológicos dos processos produtivos. Por fim, nos capítulos seguintes é definida a educação de jovens e adultos, a educação profissional e tecnológica, a educação superior e a educação especial (BRASIL, 2015).

Conforme o previsto no artigo $\mathrm{n}^{\mathrm{o}}$. 214 da Constituição de 1988, o Plano Nacional de Educação é um instrumento de planejamento do Estado, trabalhando 
com políticas públicas educacionais para o aprimoramento da educação. Também são definidas metas para o ensino em todos os níveis por dez anos, com vigência atual de 2014 a 2024. Entre suas metas, podemos mencionar a erradicação do analfabetismo, melhoria da qualidade da educação e a valorização dos profissionais de educação (BRASIL, 2014).

Sobre o planejamento da educação, a Lei de Diretrizes e Bases da Educação determina que sejam estabelecidas pela União em conjunto com Estados e municípios as diretrizes para a educação básica que nortearão os currículos e seus conteúdos assegurando uma formação básica comum (BRASIL, 2013).

Quando Cabral descobriu "a nova terra" no século XVI, os habitantes que aqui viviam estavam em contato direto com a natureza. $\mathrm{O}$ ambiente natural exigia $\mathrm{O}$ uso da força física para a manutenção da vida. Nos combates entre grupos e animais selvagens, os mais fortes e mais habilidosos eram aqueles quem sobreviviam, uma forma de seleção natural. Não apenas lutar, mas, para sobreviver, era preciso manejar bem o arco e flecha, pescar, caçar, nadar, correr e dominar a canoagem (MARINHO, 1979).

Na Europa, entre os séculos XVIII e XIX, a sociedade capitalista se consolidava - os exercícios físicos tinham grande valor. Um homem mais forte, mais resistente, mais ágil era necessário para produzir riqueza. Aqueles que não possuíam os meios de produção tinham apenas sua força de trabalho como mercadoria para vender e garantir sua sobrevivência. O caçar, o pescar, o domínio do arco e da flecha já não mais eram as principais ferramentas para a conquista do alimento no mundo. A Revolução Industrial precisava urgente de mão de obra e trazia cada vez mais pessoas para as insalubres fábricas que cresceram junto a essa nova "civilização". Muitos abandonaram o meio rural e foram para as cidades. Como consequência da mudança de local, as condições de vida nos centros urbanos se tornavam cada vez mais degradantes, pois, em paralelo a esse crescimento, nem serviços básicos como a limpeza de ruas conseguiu absorver a chegada deste volume de gente que, nestas condições, favorecia ao aparecimento de doenças e epidemias (SOARES, 2004).

O exercício físico passou a ser considerado "remédio" para a aquisição de um corpo saudável e disciplinado para o trabalho, mesmo, sem melhorias no estilo de vida e das condições de trabalho nestes centros urbanos. As autoridades 
na Europa passaram a disseminar a ideia de "cuidados com o corpo" como, por exemplo, escovar os dentes, lavar as mãos, tomar banho e a prática dos exercícios físicos, pois, cuidar do corpo significa cuidar da nova sociedade emergente. Gente "saudável" - é igual à força de trabalho - ou seja, lucro. A classe dominante neste período reconhece a importância de manter o trabalhador "saudável" e por dirigir a nova sociedade nas esferas política, intelectual e moralmente, incluiu os exercícios físicos nos currículos escolares. Por meio de propostas de autores como Guts Muths (1712-1838), considerado o pai da ginástica pedagógica alemã, a ginástica foi incluída nas escolas considerada como "educação física". Após sistematizações e contribuições de fisiologistas e médicos, os exercícios físicos denominados agora de "Métodos Ginásticos" conquistaram espaço e respeito perante os demais componentes curriculares da escola. (COLETIVO DE AUTORES, 2012).

No Brasil, a partir de 1929 a educação física tornou-se disciplina obrigatória nas instituições de ensino a partir dos seis anos para ambos os sexos. As aulas eram ministradas por instrutores físicos do Exército que traziam consigo toda a rigidez e disciplina das instituições militares. Mantendo a educação física escolar com a identidade da instituição militar, construía-se um projeto de homem disciplinado e respeitador da hierarquia social. O auge da militarização da escola era resultado do projeto de sociedade idealizado pela ditadura militar do período histórico denominado de "Estado Novo" (COLETIVO DE AUTORES, 2012).

Após a obrigatoriedade da educação física, em 1931 foi adotado oficialmente o método francês de ginástica. Em 1933, é criada a Escola de Educação Física do Exército e em 1939 é criada a Escola Nacional de Educação Física e Desportos da Universidade do Brasil, a primeira escola civil de formação de professores de educação física. Ao final do período da ditadura do Estado Novo, concomitante ao término da Segunda Guerra Mundial, conforme Ghiraldelli Júnior (1991), a "Educação física higienista" em vigor, preocupada com a saúde, foi substituída pela "Educação Física Militarista" que visava a "amor à pátria". Porém, com o fim da guerra, esta precisava se reciclar e se livrar de seus argumentos belicosos. Houve intenso processo de difusão do esporte no sistema escolar.

$\mathrm{O}$ "esporte da escola" exigia que as aulas de educação física seguissem os códigos esportivos do rendimento e competição. A Constituição de 1937 previa 
Classificação dos ingressos na graduação em educação física referente aos conteúdos da...

obrigatoriamente a prática de exercícios físicos em todas as instituições de ensino, logo em 1942 foi permitida a entrada das práticas esportivas na escola dividindo espaço com a instrução militar. A educação física como prática educativa obrigatória tinha carga horária definida em sessões semanais, com carga horária estipulada tanto para o ensino secundário quanto para o ensino industrial. Com o golpe militar de 1964 o esporte passou a ser mais evidenciado nas escolas. Entre outras reformas educacionais, o acordo entre Brasil e Estados Unidos permitiu que vários dos professores de educação física ingressassem aos cursos de pós-graduação que focavam na prática esportiva e aptidão física. A partir disto o esporte se tornou o principal objeto das aulas de educação física. A escola deveria ser um "celeiro de atletas". Pela lei, a educação física mantinha-se como disciplina obrigatória no currículo de todos os cursos e níveis dos sistemas de ensino (PARANÁ, 2008).

De acordo com o Coletivo de Autores (2012), nas décadas de 70 e 80 surgem movimentos renovadores que criticavam a base somente esportiva da educação física. A psicomotricidade e suas variantes, por exemplo, a psicocinética de Jean Le Boulch (1978), não era um método de educação física, mas, uma teoria geral do movimento e por meio dela, seria possível educar e disciplinar o corpo, desenvolvendo também aspectos cognitivos, afetivos e motores. Porém, a psicomotricidade deixou apenas características idealistas, assim o esporte se manteve como prática corporal para a educação e disciplina de corpos.

Com o fim da ditadura militar, em 1985, ocorreu uma nova reformulação da educação no Brasil. Houve a expansão da pós-graduação, novos cursos principalmente na área da educação que permitiram maior reflexão sobre o "humano". As questões sobre a legitimidade da educação física no âmbito escolar resultaram em tendências denominadas "progressistas", destacando algumas abordagens como a "Desenvolvimentista", que priorizava o ensino de habilidades motoras em uma sequência de desenvolvimento e a "Construtivista" que focava na formação integral do sujeito, incluindo as dimensões afetivas e cognitivas ao movimento humano (PARANÁ, 2008).

Nesse período, existiam discussões no Brasil sobre "concepções pedagógicas". Havia as "concepções críticas" da educação física, a citar as concepções "críticosuperadora" e "crítico-emancipatória" que criticavam a partir da sociedade capitalista. 
A concepção "crítico-superadora" é baseada na pedagogia "histórico-crítica", onde o objeto da educação física seria a "Cultura corporal", constituída dos conteúdos: esporte, ginástica, jogos, lutas e a dança. Estes são organizados e sistematizados por seus conhecimentos acumulados historicamente, sendo retomados pelos alunos nos diferentes níveis de ensino, porém, com outros graus de complexidade. Esta abordagem foi criada na década de 90 pelo grupo de pesquisadores denominado "Coletivo de autores". A abordagem "crítico-emancipatória" basicamente entendia que a expressividade corporal é uma linguagem, por onde o homem se relaciona com o meio ambiente, tornando-se sujeito pelo reconhecimento de si no outro. Esta concepção foi criada por Elenor Kunz também na década de 90. No final dos anos 80 e o início de 1990, no Estado do Paraná houve o início das discussões para a elaboração do currículo básico da educação e da educação física (Paraná, 2008).

A disciplina de educação física foi fundamentada na pedagogia históricocrítica, reflexiva sobre a desigualdade do país, sob os pressupostos do materialismo histórico-dialético. O exercício físico "por ele mesmo" deveria ser substituído por um novo entendimento sobre o movimento humano, que passa a ser uma prática social, uma forma do homem se comunicar com o mundo, valorizando a produção histórica e cultural dos povos. Com a aprovação da LDB de 1996, o Ministério da Educação apresentou os PCN's (Parâmetros Curriculares Nacionais) incluindo a disciplina de educação física. Sucintamente, a educação no país deveria seguir a seguinte hierarquia: o determinado pela União (Parâmetros Curriculares Nacionais), os Estados desenvolverem seus programas com base nos PCN e os municípios devem obedecer às diretrizes estaduais. Os PCN para o ensino fundamental destacavam questões ligadas às dimensões culturais, sociais, políticas e afetivas relativas ao corpo e ao movimento. Já para o ensino médio receberam destaque os temas transversais, vindos da "pedagogia das competências e habilidades". Mesmo não apresentado da maneira esperada para a educação física, esta deveria permitir acesso ao conhecimento sobre as práticas corporais, estimular a crítica e a reflexão sobre o ser humano e seu contexto (PARANÁ, 2008).

Para o Coletivo de Autores (2012), os conteúdos que estruturam educação física para a educação básica são: o esporte; jogos e brincadeiras; ginástica; lutas e dança. O estudo desse conhecimento visa compreender a expressão corporal como 
uma linguagem. $\mathrm{O}$ trabalho destes conteúdos deve permitir ao aluno compreender qual relação eles têm com os grandes problemas sociais e políticos atuais, principalmente, para classe social onde está inserido.

Sucintamente, os conteúdos estruturantes são tratados de maneira que são contemplados e relacionados com aspectos políticos, históricos, sociais, econômicos, entre outros, conforme o disposto por Paraná (2008):

- Esporte: Deverá permitir aos alunos a reflexão sobre as práticas esportivas. Não se deseja a limitação ao aprendizado dos fundamentos, táticas de jogo e regras. O "histórico-social" das modalidades ao longo dos anos deve ser relevada, incluindo, recriações desta prática corporal, utilizado como ferramenta para o lazer ou manutenção da saúde e na promoção de relações sociais. Temas como profissionalização esportiva, esforços extremos, competitividade, exclusão dos menos hábeis, o sentido da competição e seu significado cultural como fenômeno de massa.

- Jogos e Brincadeiras: Os jogos permitem a percepção e interpretação da realidade. Aprende-se sobre a liberdade e os limites (regras) individuais e coletivos. São representações do mundo real por meio de situações imaginárias. Ainda, os brinquedos carregam consigo relações sociais, políticas e simbólicas da sua construção.

- Ginástica: A ginástica proporciona ao aluno conhecer as possibilidades do seu corpo, nas diferentes representações das ginásticas (imitativas de animais, práticas circenses, ginástica geral, artística e rítmica). Espera-se que o aluno questione padrões estéticos, o culto exagerado ao corpo e os modismos presentes nas variadas práticas corporais.

- Lutas: Este conteúdo deve oferecer o entendimento sobre o contexto em que as lutas eram praticadas (quais necessidades sociais, econômicas, políticas e históricas levaram o homem a praticá-las), independente da divisão cultural entre oriente e ocidente. Deixar claro aos alunos suas funções, transformações ao longo dos anos, finalidades e valores, princípios e a filosofia que as acompanha e são úteis na formação do ser humano. 
- Dança: A dança é o conteúdo que trabalha o corpo e sua sensibilidade, criatividade, suas expressões sensuais, estéticas e artísticas. Suas variações incluem danças típicas nacionais e regionais, danças folclóricas, dança de rua, dança de salão, entre outras. Também está fortemente ligada a realidade social, permitindo o homem se expressar por movimentos.

\section{DESENVOLVIMENTO}

Trata-se de pesquisa descritiva (MARTINS JUNIOR, 2013), que pretende descobrir, analisar, narrar e descrever os fatos obtidos na atualidade sobre uma determinada população como, por exemplo, nível de escolaridade, estado de saúde física e mental etc. Referente ao instrumento para coleta de dados, conforme conceitua Martins Junior (2013), estes são os meios, materiais, aparelhos, técnicas, ou seja, os elementos que foram utilizados na coleta dos dados. Nesta pesquisa os dados foram coletados por meio de questionário, elaborado pelo autor e validado por professores da instituição, formado por questões mistas, que foram respondidas pela amostra, pessoalmente aplicados pelo próprio autor.

A pesquisa foi submetida à avaliação pelo Comitê de Ética em Pesquisa (CEP) para atender aos padrões da resolução 196/96-CNS-MS e aprovada por meio do parecer $\mathrm{n}^{\circ}$. 1.195.058. O questionário foi aplicado no dia $1^{\circ}$ de setembro do ano corrente em conjunto com o TCLE (Termo de Consentimento Livre e Esclarecido). Com os questionários respondidos e os TCLE assinados, os dados foram tabulados por meio da estatística descritiva (média, desvio-padrão, distribuição de frequências e percentual, também denominado de frequência relativa), por meio do software SPSS - versão 2.0/Windows. Os dados obtidos estão dispostos em tabelas, que de acordo com Marconi e Lakatos (2011), a disposição em tabelas possibilita a maior facilidade na verificação e inter-relação entre os dados.

Os resultados visam classificar os acadêmicos em relação aos componentes da cultura corporal de acordo com o previsto nas DCE do Paraná. Ainda, tentam descobrir de maneira geral, quais habilidades motoras trazem consigo e por qual motivo escolheram a educação física como área de formação. 
Inicialmente foram feitas algumas questões sobre o perfil dos acadêmicos. A Tabela 1 - Dados gerais, mostra a idade e sexo dos participantes, onde foi calculada a idade média e o desvio-padrão. Nesta amostra, 36 sujeitos são do sexo masculino, representado $63,2 \%$ e 21 sujeitos do sexo feminino, representando $36,8 \%$. A idade média para os homens foi de 20 anos e para as mulheres de 19,52, com os respectivos desvios de 2,532 e 1,965. No total, a média de idade foi de 19,91 anos com desviopadrão de 2,340, a seguir:

Tabela 1. Dados gerais

\begin{tabular}{lcccc}
\hline \multicolumn{1}{c}{$\mathbf{n}(\mathbf{5 7 )}$} & Frequência & $\%$ & Média - Idade & Desvio-padrão \\
\hline Masculino & 36 & $63,2 \%$ & 20,14 & 2,532 \\
Feminino & 21 & $36,8 \%$ & 19,52 & 1,965 \\
\hline TOTAL & 57 & $100 \%$ & 19,91 & 2,340 \\
\hline
\end{tabular}

Sobre as modalidades de ensino médio, cursadas pelos acadêmicos, $84,2 \%$ cursaram o ensino médio "geral", aqui considerado como a modalidade que visa à aprovação no vestibular. Temos 10,5\% que cursaram o ensino médio com formação profissional e/ou técnica e 5,3\% concluíram o ensino médio por meio da educação para Jovens e Adultos (EJA). Sobre o tipo de instituição de ensino, 84,2\% dos participantes estudaram em escolas públicas e 15,8\% em escolas privadas. E sobre o período em que os alunos cursaram a maior parte do ensino médio, 80,7\% o cursaram no período da manhã, $1,8 \%$ no período da tarde e $17,5 \%$ no período noturno.

Na Tabela 2 são reúnidos os questionamentos em relação aos elementos da cultura corporal (esporte, jogos e brincadeiras, dança, ginástica e lutas) trabalhados no ensino médio. Em cada um destes elementos foi questionado: 1) se aprenderam sobre os contextos das modalidades (histórico, social, econômico e político) e a influência da mídia/indústria cultural; 2) a relação destas práticas com a saúde e qualidade de vida; 3) se aprenderam somente a parte "prática"; 4) se dominam todas estas esferas (seus contextos, relação com a saúde/qualidade de vida e a parte prática) e 5) não entende o conteúdo abordado, conforme o exposto. 
Tabela 2. Conteúdos trabalhados da cultura corporal

\begin{tabular}{|c|c|c|c|c|c|c|c|c|c|c|}
\hline \multirow{2}{*}{ n (57) } & \multicolumn{2}{|c|}{ Esporte } & \multicolumn{2}{|c|}{$\begin{array}{c}\text { Jogos e } \\
\text { brincadeiras }\end{array}$} & \multicolumn{2}{|c|}{ Dança } & \multicolumn{2}{|c|}{ Ginástica } & \multicolumn{2}{|c|}{ Lutas } \\
\hline & Freq & $\%$ & Freq & $\%$ & Freq & $\%$ & Freq & $\%$ & Freq & $\%$ \\
\hline $\begin{array}{l}\text { Entende o contexto } \\
\text { histórico, social, } \\
\text { econômico e } \\
\text { político. }\end{array}$ & 25 & $43,9 \%$ & 8 & $14,0 \%$ & 12 & $21,1 \%$ & 7 & $12,3 \%$ & 16 & $28,1 \%$ \\
\hline $\begin{array}{l}\text { Entende a relação } \\
\text { com saúde e } \\
\text { qualidade de vida. }\end{array}$ & 2 & $3,5 \%$ & 19 & $33,3 \%$ & 7 & $12,3 \%$ & 8 & $14,0 \%$ & 3 & $5,3 \%$ \\
\hline $\begin{array}{l}\text { Entende na } \\
\text { "prática". }\end{array}$ & 6 & $10,5 \%$ & 15 & $26,3 \%$ & 18 & $31,6 \%$ & 3 & $5,3 \%$ & 6 & $10,5 \%$ \\
\hline $\begin{array}{l}\text { Entende todos os } \\
\text { itens anteriores. }\end{array}$ & 3 & $5,3 \%$ & 2 & $3,5 \%$ & 2 & $3,5 \%$ & 0 & $0,00 \%$ & 2 & $3,5 \%$ \\
\hline $\begin{array}{c}\text { Não entende } \\
\text { nenhum dos itens. }\end{array}$ & 21 & $36,8 \%$ & 13 & $22,8 \%$ & 18 & $31,6 \%$ & 39 & $68,4 \%$ & 30 & $52,6 \%$ \\
\hline TOTAL & 57 & $100 \%$ & 57 & $100 \%$ & 57 & $100 \%$ & 57 & $100 \%$ & 57 & $100 \%$ \\
\hline
\end{tabular}

*Freq: Frequência

Referente ao conteúdo "Esporte", 43,9\% entendem sobre o contexto histórico, social, econômico e político das modalidades e 3,5\% a relação do esporte com a saúde e/ou qualidade de vida; 10,5\% afirmam entender na prática (regras, fundamentos, técnicas e tática, ou poderia ser atleta). Já 5,3\% dominam todas as esferas (históricos, relação com a saúde, prática) e 36,8\% não entendem nenhum dos itens descritos.

Em relação aos jogos e brincadeiras, 14,0\% entendem o contexto histórico e social, 33,3\% sua relação com saúde e qualidade de vida. Sabem "jogar" na prática $26,3 \%$ e $3,5 \%$ dominam todos os itens; $22,8 \%$ não entendem sobre jogos e brincadeiras.

Referente ao conteúdo Dança, 21,1\% entendem seus contextos, 12,3\% entende a sua relação com a saúde ou qualidade de vida, 31,6\% responderam que 
sabem dançar na prática, 3,5\% dominam todas as esferas e 31,6\% não entendem sobre os contextos, a relação com a saúde e/ou qualidade de vida e na prática.

Sobre o conteúdo Ginástica, 12,3\% entendem sobre o contexto histórico, social, econômico e político; $14,0 \%$ compreendem a relação da ginástica com a saúde e/ou qualidade de vida e apenas 5,3\% os que a dominam na "prática". Não houve respostas para o domínio de todas as esferas e $68,4 \%$ responderam não entender sobre nenhum dos itens anteriores.

Por fim, para os conteúdos Lutas e Capoeira, enquanto jogo, luta e dança, 28,1\% entendem seus contextos, $5,3 \%$ apenas compreendem a relação das lutas com a saúde/qualidade de vida e $10,5 \%$ responderam que sabem lutar na prática. Somente $3,5 \%$ entendem todos os itens e $52,6 \%$ não entendem sobre as lutas e capoeira.

A última questão buscou descobrir a razão pela qual os ingressantes optaram por cursar a graduação em educação física. O "futebol/futsal" foi o motivo que mais apareceu nos questionários com 15 contagens. O item "academia" apareceu em segundo lugar com dez contagens (sem descrever quais serviços ofertados pelas academias). O "voleibol" e "gosto por esportes" apareceu em terceiro lugar com sete contagens, seguido pela musculação e os quatro esportes tradicionais com bola (futsal, handebol, basquete e voleibol) somaram cinco ocorrências, ocupando o quarto lugar. Em seguida, outros motivos foram citados para a escolha da educação física, porém, optou-se por não mencionar as contagens pela pequena diferença entre os termos, respectivamente, classificados em: dança, incentivo da família, promoção da saúde, melhorar a educação física escolar e trabalhar com alto rendimento, atletismo, capoeira, práticas circenses, skate, tênis, squash ou tênis de mesa.

O objetivo do presente estudo não é criticar o currículo proposto e nem as correntes pedagógicas que podem ser utilizadas na educação. Mas, verificar quais as contribuições que a educação física trouxe a estes alunos nos últimos anos. As questões referentes aos elementos da cultura corporal permitiram que a amostra relatasse um pouco de como estes conteúdos foram trabalhados. Sobre o conteúdo "esporte" verificou-se que as modalidades com bola (futebol/futsal, voleibol, handebol e basquete) apareceram com mais frequência. O "excesso" de aulas práticas "livres", vulgo "rola bola" ou aula "recreativa" foram os relatos que mais apareceram sobre como o esporte foi trabalhado. 
De acordo com a Tabela 2 - Conteúdos trabalhados, 36,8\% relataram não entender sobre os contextos dos esportes, a relação com saúde e qualidade de vida ou sobre o esporte na "prática". Em contrapartida, apenas 5,3\% alegam entender sobre as três esferas. Este valor merece atenção, pois, conforme os trabalhos de Silva (2009, 2012 e 2013), os esportes tradicionais (futebol e voleibol) são os principais esportes trabalhados no ensino fundamental, formando uma "monocultura corporal de movimento". Mesmo se falando de uma "monocultura", poucos ex-alunos afirmaram dominar uma modalidade esportiva.

Sobre o conteúdo Jogos e Brincadeiras, percebeu-se que os egressos são mais esclarecidos sobre o assunto - 22,8\% escolheram a opção que não entendia sobre jogos e brincadeiras e 3,5\% alegaram dominar todos os itens. Silva (2009) em sua pesquisa demonstrou que os conteúdos mais explorados nas séries iniciais do ensino fundamental foram o futebol e os jogos tradicionais, mesmo com as diferenças geográficas.

Falando sobre o conteúdo Dança, 31,6\% crêem não entender sobre este conteúdo contra 3,5\% que responderam entender todos os itens. Os relatos sobre a questão da dança justificam que a mesma só foi trabalhada até o quinto ano, ou em datas comemorativas. Em particular, um dos relatos chamou a atenção por conter a seguinte sentença: "A escola não é uma festa e sim um lugar de estudo". Isto aponta que mais reflexões sobre a dança são necessárias tanto no ensino básico quanto no ensino superior. Em sua pesquisa, KLEINUBING, SARAIVA, FRANCISCHI (2013) também mencionaram que oferecer mais oportunidades de vivência e reflexão sobre a dança e a desconstrução da imagem de que "dança é coisa de menina".

O conteúdo "Ginástica" reuniu $68,4 \%$ da amostra que assumiram não entender sobre este conteúdo e sem ocorrências para o entendimento de todas as esferas. A DCE (PARANA, 2008) sugere que no ensino médio, a ginástica deveria trabalhar também conteúdos como a relação sedentarismo, resistência, força, frequência cardíaca, desvios posturais etc. Reunindo os relatos sobre a modalidade, a "falta de estrutura" e que "tiveram que buscar sobre ginástica fora da escola" seriam os motivos para não entenderem sobre ginástica. Outro relato merece destaque nesta questão, o texto dizia "não teve (ginástica na escola) e quando se formar não vai apresentar aos alunos". Bezerra (2014) verificou em sua pesquisa 
que a formação inicial do professor de educação física sobre a ginástica também necessita de reestruturação em seu currículo, podendo ser uma das causas da baixa oferta destes conteúdos aos discentes.

Por fim, o conteúdo "Lutas", que na DCE engloba a Capoeira, 28,1\% entenderam os contextos histórico, social, econômico e político onde as lutas/ capoeira estão inseridas. Que compreende a relação das lutas com a saúde e qualidade de vida somam 5,3\% e 10,5\% entenderam a luta/capoeira na "prática" (fundamentos, regras, técnicas e táticas). Apenas 3,5\% compreendem as lutas integralmente e 52,6\% não entendem sobre as lutas/capoeira. Os relatos que mais apareceram foram a "falta de recursos" para as aulas e "buscaram este conhecimento fora da escola". De acordo com Correia (2015), os fatores que poderiam justificar a fragilidade deste conteúdo no contexto escolar seria, em primeiro lugar, o fato de que a educação física e as artes marciais são instituições distintas, mas, a educação física está se "apropriando" das lutas na tentativa de sistematizar este conteúdo como escolar. O segundo fator seria a limitação do ensino das lutas no processo de formação docente, já que nem todos os futuros professores praticavam artes marciais.

\section{CONSIDERAÇÕES FINAIS}

Ao final, alcançando o objetivo proposto, conseguimos classificar o conhecimento dos ingressantes na graduação em educação física pelos itens que demonstram mais conhecimentos na seguinte ordem: jogos e brincadeiras, dança, esportes, lutas e ginástica.

A contribuição deste trabalho está no planejamento da educação para novos profissionais da área. Por exemplo, quando se procura um emprego é comum o candidato passar por um processo seletivo que avalia suas capacidades. Adaptando o processo seletivo, temos resultados que mostram que estes alunos matriculados no primeiro ano têm uma bagagem "carente".

Por estes dados sabemos os pontos fracos destes alunos, situação esta, que permite o direcionamento de esforços para melhorar a formação destes sujeitos, por exemplo, aumentando a carga horária dos itens que apresentaram menor domínio como a ginástica e as lutas. Algumas limitações ocorreram no decorrer da 
pesquisa. Houve grande parcela dos acadêmicos que se recusaram a responder o questionário e foi complexo "quantificar conhecimento". Desta lição, fica a sugestão para melhorias em trabalhos futuros.

Por fim, os motivos mais decorrentes para a escolha destes acadêmicos em cursar educação física são organizados em primeiro lugar pelo futebol/futsal, em segundo lugar a academia (sem mencionar quais os serviços prestados), em terceiro lugar o voleibol/gosta de esportes e em quarto lugar a musculação/esportes com bola (basquetebol, futebol, handebol, voleibol).

\section{REFERÊNCIAS}

BRASIL. Constituição (1988). Constituição da República Federativa do Brasil: texto constitucional promulgado em 5 de outubro de 1988, com as alterações adotadas pelas Emendas constitucionais $\mathrm{n}^{\mathrm{O}} \mathrm{s}$ 1/1992 a 86/2015, pelo Decreto legislativo ${ }^{0}$ 186/2008 e pelas Emendas constitucionais de revisão no ${ }^{\circ} 1$ a 6/1994. 45. ed. Brasília: Câmara dos Deputados, Edições Câmara, 2015. Disponível em: $<$ www.camara.leg.br/editora > Acesso em: 02 jun. 2015.

BRASIL. Lei Darcy Ribeiro (1996). LDB nacional [recurso eletrônico]: Lei de diretrizes e bases da educação nacional: Lei $n^{0}$ 9.394, de 20 de dezembro de 1996, que estabelece as diretrizes e bases da educação nacional. - 11. ed. - Brasília: Câmara dos Deputados, Edições Câmara, 2015. Disponível em: <www.camara.leg. br/editora > Acesso em: 02 jun. 2015.

BRASIL. Plano Nacional de Educação (PNE). Plano Nacional de Educação 20142024. Lei $\mathrm{n}^{\mathrm{O}} 13.005$, de 25 de junho de 2014, que aprova o Plano Nacional de Educação (PNE) e dá outras providências. Brasília: Câmara dos Deputados, Edições Câmara, 2014. Disponível em: <www.camara.leg.br/editora > Acesso em: 03 jun. 2015.

BRASIL. Ministério da Educação. Secretaria de Educação Básica. Secretaria de Educação Continuada, Alfabetização, Diversidade e Inclusão. Secretaria de Educação Profissional e Tecnológica. Conselho Nacional da Educação. Câmara Nacional de 
Educação Básica. Diretrizes Curriculares Nacionais Gerais da Educação Básica. Ministério da Educação. Secretaria de Educação Básica. Diretoria de Currículos e Educação Integral. Brasília: MEC, SEB, DICEI, 2013. Disponível em: < www.mec. gov.br> Acesso em: 03 jun. 2015.

COLETIVO DE AUTORES. Metodologia do ensino de educação física. 2. ed. São Paulo: Cortez, 2012.

CORREIA, W. R. Educação física escolar e artes marciais: entre o combate e o debate. Rev. bras. educ. fís. Esporte, São Paulo, v. 29, n. 2, p. 337-344, june 2015. Disponível em: <http://www.scielo.br/scielo.php?script=sci_arttext\&pid=\$1807$55092015000200337 \& \operatorname{lng}=$ en\&nrm $=$ iso $>$. Acesso em: 22 out. 2015.

GHIRALDELLI JÚNIOR, P. Educação física progressista: a pedagogia crítico-social dos conteúdos e a Educação Física Brasileira. 10. ed. São Paulo, Loyola, 1991.

KLEINUBING, N. D; SARAIVA, M. C.; FRANCISCHI, V. G. A dança no Ensino Médio: reflexões sobre estereótipos de gênero e movimento. Rev. educ. fis. UEM, Maringá, v. 24, n. 1, p. 71-82, mar. 2013. Disponível em: < http://www.scielo.br/scielo. php?script $=$ sci_arttext\&pid $=\$ 1983-30832013000100008 \& \operatorname{lng}=$ en\&nrm $=i s o>$. Acesso em: 06 set. 2015.

LIBÂNEO, J. C. Didática. São Paulo: Cortez, 1994.

MARCONI, M. A.; LAKATOS, E. M. Metodologia cientifica. 5. ed. São Paulo: Atlas, 2011.

MARINHO, I. P. História da educação física no Brasil. São Paulo: Cia. Brasil, 1979.

MARTINS JUNIOR, J. Como escrever trabalhos de conclusão de curso: instruções para planejar e montar, desenvolver, concluir, redigir e apresentar trabalhos monográficos e artigos. 7. ed. Petrópolis: Vozes, 2013.

PARANÁ. Diretrizes curriculares da educação básica: educação física. Paraná: Secretaria de Estado da Educação Básica; Departamento de Educação Básica, 2008. 
RODRIGUES, D. F. et al. História da educação no Brasil e a prática docente diante das novas tecnologias. In: SEMINÁRIO NACIONAL DE ESTUDOS E PESQUISAS "HISTÓRIA, SOCIEDADE E EDUCAÇÃO NO BRASIL", 9., 2012, João Pessoa. Anais Eletrônicos... João Pessoa: UFPB, 2012. Disponível em: < http://www.histedbr. fe.unicamp.br/acer_histedbr/seminario/seminario9/> . Acesso em: 10 jun. 2015.

SAVIANI, D. História da História da Educação no Brasil: um balanço prévio e necessário. EccoS-Revista Científica, v. 10, p. 147-67, 2008. Disponível em: $<$ http://www.uninove.br/PDFs/Publicacoes/eccos/eccos_v10nesp/eccosv10nesp\%20 3f09.pdf $>$. Acesso em: 22 out. 2015.

SILVA, J. V. P. da. Prática pedagógica em educação física nos anos iniciais do ensino fundamental. Pensar a Prática, v. 16, n. 1, mar. 2013. ISSN 1980-6183. Disponível em: <http://revistas.jatai.ufg.br/index.php/fef/article/view/16421/13765>. Acesso em: 14 set. 2015.

SILVA, J. V. P. da; DAGOSTIN, K. U. D.; NUNEZ, P. R. M. Educação Física e conteúdos trabalhados nas séries iniciais do Ensino Fundamental. Motriz rev. educ. fís.(Impr.), v. 15, n. 3, p. 592-599, 2009. Disponível em: <www.periodicos.rc.biblioteca.unesp. br/index.php/motriz/article/view/2945/2476> . Acesso em: 06 set. 2015.

SILVA, J. V. P. da; SAMPAIO, T. M. V. Os conteúdos das aulas de educação física no ensino fundamental: o que mostram os estudos?. Revista Brasileira de Ciência e Movimento, v. 20, n. 2, p. 106-118, 2012. Disponível em: < portalrevistas.ucb.br/ index.php/RBCM/article/viewArticle/3007> . Acesso em: 06 set. 2015.

SOARES, C. L. Educação física: raízes europeias e Brasil. 3. ed. São Paulo: Autores Associados, 2004.

Recebido em: 26 de novembro de 2016 Aceito em: 10 de abril de 2017 